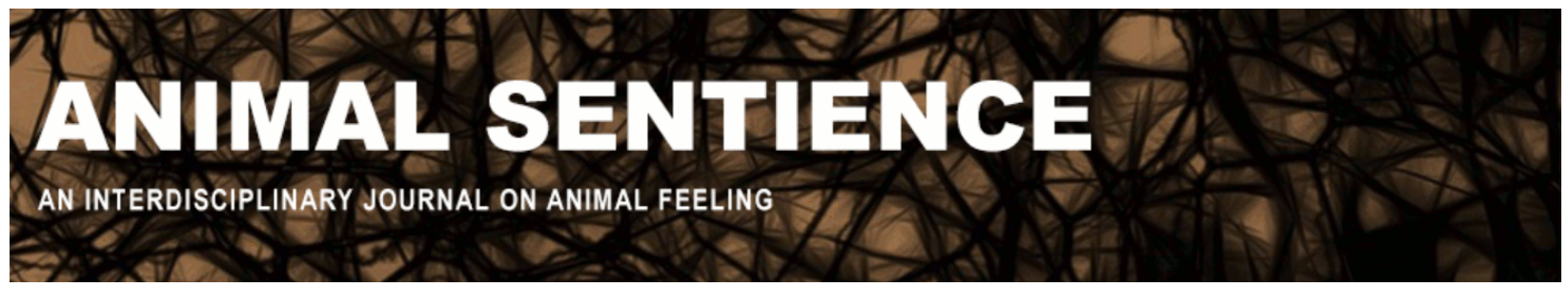

Rowlands, Mark (2016) Mentality and animal welfare. Animal Sentience 5(9) DOI: $10.51291 / 2377-7478.1007$

Date of submission: 2015-03-24

Date of acceptance: 2015-12-13

(c) (i)




\title{
Mentality and animal welfare
}

Commentary on Broom on Animal Welfare

\author{
Mark Rowlands \\ Department of Philosophy \\ University of Miami
}

\begin{abstract}
In this commentary I discuss the concept of sentience as used in Broom's book Sentience and Animal Welfare (2014). Broom's understanding of sentience is, I suggest, both misleading and revealing. Appreciating why this is so is important for understanding the connection between the mental life of animals and their moral status.
\end{abstract}

Mark Rowlands mrowlands@miami.edu is Professor of Philosophy, University of Miami. He studies the philosophy of mind, ethics and moral psychology. Mark wrote 17 books, including Animal Rights (Macmillan 1998), The Environmental Crisis (Macmillan, 2000), Animals Like Us (Verso, 2002), The

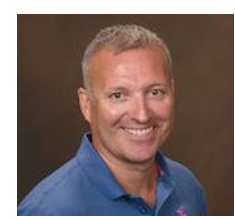
Philosopher and the Wolf (Granta, 2008), and Can Animals be Moral? (Oxford, 2012). http://www.as.miami.edu/phi/people/

Rejecting simple accounts of sentience as a matter of "having the capacity to feel," Broom (2014) offers his own definition:

"A sentient being is one that has some ability: (i) to evaluate the actions of others in relation to itself and third parties; (ii) to remember some of its own actions and their consequences; (iii) to assess risks and benefits; (iv) to have some feelings; and (v) to have some degree of awareness." (p. 6)

Two things are immediately noticeable about this definition. First, it is highly intellectualist: being sentient requires fairly sophisticated cognitive abilities - to evaluate, assess, and remember. Second, there is a danger of circularity, courtesy of condition (v). To avoid this, we will need a way of specifying what awareness is that does not make it conceptually tied to the idea of awareness. Perhaps aware of this, Broom does offer an account of awareness: "[A]wareness is a state during which concepts of the environment, of self, and of self in relation to environment result from complex brain analysis of sensory stimuli or concepts based on memory" (p. 7).

Even if this definition is adequate, it only exacerbates the intellectualization evident in the definition of sentience; now awareness is seen to require both concepts and self-awareness. Even if we are liberal in our understanding of concepts and self-awareness, this threatens to restrict sentience to a small range of species. The rest of the book is a wide-ranging discussion of 
mentality in nonhuman animals, including feelings, moods, emotions, cognition, metacognition, self-awareness, and even the capacity for morality. It should be evident, therefore, just how far removed Broom's concerns are from the traditional understanding of sentience as having the capacity to feel. The question is what to make of this?

An uncharitable reaction would be to dismiss Broom's definition as based on a confusion of sentience and mentality more generally. However, I suspect that what is really going on is far more interesting, and Broom's conception is, in fact, to be commended. In the early days of the contemporary animal rights/liberation movement - in the 1970s/1980s - the focus was, justifiably, on the extraordinary suffering we inflict on huge numbers of animals in the service of human interests that are, almost always, comparatively trivial. Given the heartbreaking predicament of these animals, it is entirely understandable that the focus was on their capacity to suffer. Moreover, sentience is still by far the most plausible sufficient condition for moral standing: if a creature is sentient, there can be no moral justification for refusing to take its interests into account. However, there is far more to many animals than mere sentience. And to focus on sentience alone has its dangers.

Suppose, for example, we were tempted to think of a child as merely a receptacle of pleasure and pain. With such a view, we would conclude that the best possible life for this child would be a life with as much pleasure and as little pain in it. However, if this were our only focus, the life of this child would be a sad waste. The reason is that the child has so many other abilities intellectual, emotional, social, and athletic - and to live a remotely worthwhile life, he or she needs to be allowed to develop these abilities. Similarly, the life of a well-fed dog with a comfortable sofa to sleep on is inordinately better than the life of a veal calf, battery hen, or crated sow. But if that is all the dog's life is, it is still a very long way from a good, fulfilling, canine life.

The moral is this: sentience is a plausible sufficient condition for moral standing. If a creature is sentient, we are morally obliged to take his or her interests into account. However, we cannot know what this means - what this requires of us - until we know what those interests are. And we cannot understand those interests until we understand the full gamut of interests and abilities possessed by creatures of that sort.

Accordingly, Sentience and Animal Welfare is best seen as part of the recent broadening of our moral understanding of animals. To properly understand what morality requires of us with respect to animals requires that we properly understand animals, and their species-specific, and often individual, capabilities. We must always accord due importance not only to pleasure and pain, but also to the things that drive animals, that motivate them, that make their lives worth living-not simply reduce them to the relative amounts of pleasure and pain in those lives. Seen in this light, Broom's book is an excellent contribution towards this broadened understanding of animals and the moral implications that ensue from it.

\section{References}

Broom, D.M. (2014) Sentience and animal welfare. Wallingford: CABI. 